\title{
El régimen fiscal de las cooperativas y el Derecho de la Unión Europea ${ }^{1}$ Cooperative taxation and European Union Law
}

\author{
Marina Aguilar Rubio²
}

Universidad de Almería (España)

Sumario: I. Introducción. II. La justificación de los beneficios fiscales al cooperativismo en reconocimiento a las limitaciones de su régimen jurídico y económico y a su función social. III. La revisión de los beneficios fiscales aplicables a las cooperativas en virtud del régimen de ayudas de Estado de la Unión Europea. IV. Las bases para un cambio de tendencia: la sentencia del TJUE en el caso de las cooperativas italianas y la resolución del caso español. V. Notas conclusivas. VI. Bibliografía.

Summary: I. Introduction. II. The justification of tax benefits to cooperatives in recognition of the limitations of their legal and economic system and its social function. III. The review of tax benefits applicable to cooperatives under state aid scheme of the European Union. IV. The basis for a turnaround: the ECJ ruling in the case of Italian cooperatives and resolution of the Spanish case. V. Concluding remarks. VI. Bibliography.

Resumen: El régimen jurídico y económico de las cooperativas presenta una serie de limitaciones que, en gran medida, derivan del respeto a los principios cooperativos y de concepciones restrictivas del concepto de cooperativa y de cooperativismo. En atención a sus particularidades, las legislaciones de algunos Estados miembros de la Unión Europea contienen una fiscalidad de todas o algunas cooperativas que toma en consideración esta realidad. Esto ha generado algunas controversias con la interpretación del Derecho de la Unión Europea realizada por algunas Instituciones.

El estudio realiza un recorrido sobre las actuaciones de las Instituciones de la Unión Europea en relación con las medidas fiscales específicas de las coope-

1 Estudio realizado en el marco del Proyecto de Investigación del Ministerio de Economía y Competitividad: «Integración cooperativa y reestructuraciones socialmente responsables. Mecanismo de creación e empleo e incremento de productividad empresarial» (DER2013-48864-C2-1-P).

2 Profesora Contratada Doctora (acreditada a Titular de Universidad) de Derecho Financiero y Tributario. Correo electrónico: magui@ual.es 
rativas con objeto de enmarcar correctamente la situación jurídica actual de estas sociedades y valorar la necesidad de reforma de su régimen legal y, en su caso, los términos de la misma.

Palabras clave: Tributación, Cooperativas, Unión Europea, Reforma legal.

Abstract: The cooperative legal and economic system has a number of limitations that, largely, derivate from respect to cooperative principles and restrictive conceptions of cooperative and cooperativism concepts. In view of their particularities, the laws of some Member States of the European Union contain a taxation of all or some cooperatives which takes into account this reality. This has generated some controversy with the interpretation of European Union law by some Institutions.

The study addresses the position of the Institutions of the European Union regarding the specific tax measures applicable to cooperatives in order to properly frame the current status of these societies and consider the need to reform its legal system and, where appropriate, the terms of it.

Key words: Taxation, Cooperatives, European Union, Legal Reform. 


\section{Introducción}

El régimen jurídico y económico de las cooperativas presenta una serie de limitaciones que, en gran medida, derivan del respeto a los principios cooperativos y de concepciones restrictivas del concepto de cooperativa y de cooperativismo ${ }^{3}$. Sobre el sector cooperativo pesan además determinadas cargas fiscales y parafiscales que suponen una evidente rémora para sus sociedades que, en muchas ocasiones, no resulta compensada por el trato fiscal especial, pero cada vez menos privilegiado, del que disfrutan.

España no es el único país que regula un régimen fiscal específico para las cooperativas. Las legislaciones de algunos Estados miembros de la Unión Europea contienen una fiscalidad de todas o algunas cooperativas más favorable que la de las sociedades de capital. La posibilidad de establecer un régimen fiscal privilegiado se ha asociado tradicionalmente a la naturaleza singular del capital y de los beneficios cooperativos. Pero no sólo su especialidad, derivada del diferente régimen económico, político y social de las cooperativas respecto al del resto de las sociedades de nuestro ordenamiento, justifica la necesidad de un tratamiento diferenciado para este tipo de sociedades. Éste responde también al mandato constitucional a los poderes públicos de fomentar mediante una legislación adecuada las sociedades cooperativas y, como no, a su función social, en particular, en cuanto que facilitan el acceso de los trabajadores a los medios de producción y promueven la adecuada formación de los mismos a través de las correspondientes dotaciones de fondos realizadas con esta finalidad. Dicho de otro modo, «ya que buena parte del patrimonio social obtenido con el esfuerzo particular de sus miembros termina revertiendo a la comunidad, parece lógico que las cooperativas con contribuyan al sostenimiento de las cargas públicas destinando un menor porcentaje de sus beneficios regulares o periódicos al pago de impuestos» (Rodrigo Ruiz 2010, 12-13).

Estas consideraciones llevaron a la promulgación de normas fiscales especiales, que se materializaron, primero, en el Estatuto Fiscal de las Cooperativas, aprobado por Decreto 888/1969, de 9 de mayo en la etapa preconstitucional y, después, en la vigente Ley 20/1990, de 19 de diciembre, de Régimen Fiscal de las Cooperativas (junto a las leyes forales sobre la materia: Ley Foral 9/1994, de Régimen Fiscal de las Cooperativas Navarras; Ley Foral 2/1997, de Régimen Fiscal de las

3 Para profundizar en esta cuestión, Marina Aguilar Rubio, Los principios cooperativos en la legislación tributaria (CIRIEC-España, Revista Jurídica de Economía Social y Cooperativa, . $\left.^{\circ} 27,2015\right)$ passim. 
Cooperativas del territorio histórico de Guipúzcoa; Ley Foral 9/1997, de Régimen Fiscal de las Cooperativas del territorio histórico de Vizcaya y Ley Foral 16/1997, de Régimen Fiscal de las Cooperativas del territorio histórico de Álava).

Esta Ley, como su propia exposición de motivos indica, contiene dos tipos esenciales de normas que explican el verdadero tratamiento fiscal de estas sociedades: por una parte, existen normas incentivadoras que establecen beneficios fiscales reconocidos a las cooperativas «protegidas» y «especialmente protegidas» (arts. 33 y ss.); y por otra parte, hay normas técnicas o de ajuste que adaptan las reglas generales de tributación a las peculiaridades propias del funcionamiento de las cooperativas y que se engloban bajo la rúbrica de «Reglas especiales aplicables al Impuesto sobre Sociedades» (arts. 15 y ss.)

El régimen ha recibido duras críticas desde el principio, pues el disfrute de los regímenes de protección fiscal y, sobre todo, de especial protección fiscal, está sometido a unas exigencias tan duras que las más de las veces resultan paradójicamente desincentivadoras de la toma de iniciativas empresariales, sociales o laborales (Rodrigo Ruiz 2010, 11; Hinojosa Torralvo 2010, 75-76). Ello ha llevado a algún sector de doctrina muy autorizado a plantear, desde hace ya muchos años, la necesidad de un cambio profundo en el mencionado régimen fiscal (Alguacil Marí, 2003, passim).

En España, la protección fiscal que reciben las cooperativas se anuda directamente con el elemento mutual inherente a dichas entidades.

Por un lado, el art. 13 Ley 20/1990 impone como requisito para mantener la condición de cooperativa fiscalmente protegida no superar el $50 \%$ del volumen total de operaciones de la cooperativa en operaciones con terceros no socios.

Por otro lado, solo los resultados denominados cooperativos -los provenientes de la actividad cooperativa o cooperativizada - tienen establecido un tipo de gravamen bonificado en el Impuesto sobre Sociedades, que es donde se concentra el grueso de las bonificaciones más relevantes. Ello implica al menos dos consecuencias: una, que los resultados extracooperativos tributarán al tipo de gravamen general establecido en cada momento en el Impuesto sobre Sociedades (25\% desde el presente ejercicio) y ello a pesar de que se destinen por imperativo legal a dotar los fondos irrepartibles de las cooperativas -Fondo de Reserva Obligatoria (FRO) y Fondo de Educación y Promoción (FEP) - por lo que soportan una carga económica añadida derivada de las restricciones en el poder de disposición que la irrepartibilidad de dichos fondos comporta; y otra, que la base imponible del Impuesto sobre So- 
ciedades se desdobla para las cooperativas en dos clases de resultados - los cooperativos y los extracooperativos - sometidos a tipos de gravamen distintos - 20\% y $25 \%$ respectivamente-, lo que conduce a un régimen aplicable caracterizado por su alta complejidad y por las diferencias que guarda respecto a la regulación general.

Y por último, las cooperativas especialmente protegidas, las únicas que disfrutan de una bonificación sustancial del $50 \%$ en la cuota íntegra, deben cumplir con unas rigurosas exigencias de carácter mutual en el desarrollo de su actividad.

Pero es que, además, buena parte de los incentivos fiscales regulados en la Ley 20/1990 ha perdido el alcance y los efectos que tenía inicialmente. Así, la extensión de la exención por operaciones societarias a múltiples y nuevos supuestos en virtud de otras normas fiscales o la exoneración tributaria generalizada en el Impuesto sobre Actividades Económicas - que solo excluye a personas jurídicas con un volumen de negocio superior a un millón de euros - , relativizan en gran medida el alcance de los incentivos recogidos en la citada Ley. A mayor abundamiento, la rebaja generalizada que los tipos impositivos en el Impuesto sobre Sociedades que se produjo a partir del ejercicio 2008 (del 35\% al $30 \%$ ) y que no se ha extendido a las cooperativas, cuyo tipo reducido de gravamen se ha mantenido, supone la restricción más significativa desde un punto de vista comparativo. Tal es su alcance, que muchas cooperativas se inclinan por no aplicar el régimen fiscal de las cooperativas, por considerarlo perjudicial, y cumplen sus obligaciones tributarias por este impuesto con arreglo al régimen general, mediante la simple argucia de no realizar contabilidad separada de las operaciones con terceros no socios, lo que se considera causa de pérdida de la condición de cooperativa fiscalmente protegida en la Ley 27/1999, de 16 de julio, de Cooperativas (LCOOP). Esto es, tributan en el Impuesto sobre Sociedades en pie de igualdad con el resto de entidades no cooperativas en cuanto a las denominadas normas de incentivo, aunque observando, en todo caso, las normas técnicas o de ajuste fijadas en la Ley 20/1990.

Hace ya algún tiempo que desde el sector se demandan sociedades simples, flexibles, competitivas y modernas que ofrezcan suficientes garantías en el tráfico mercantil, como requisitos imprescindibles para la pervivencia y viabilidad económica de las cooperativas. Pero ello debe combinarse con el debido respeto a los principios cooperativos, lo que obviamente hace que la tarea no sea fácil (Vargas Vasserot 2009, 6163). Algunos legisladores autonómicos, que se han atrevido a abordar la cuestión, han llevado a cabo una profunda adaptación del modelo cooperativo a los nuevos tiempos, aun a sabiendas de que ello com- 
porta la exclusión del régimen fiscal aplicable a las cooperativas. Este ejemplo, como algunos otros que iremos destacando, pone de manifiesto que el ejercicio de las competencias normativas autonómicas está desviando el régimen jurídico de las cooperativas del que existía en los años noventa del pasado siglo y ello tendría que tener reflejo en el régimen fiscal correspondiente.

Por si las críticas desde el propio sector no fueran suficientes, las Instituciones de la Unión Europea han desarrollado diversas actuaciones contra ciertas medidas fiscales de protección a las cooperativas adoptadas por algunos de sus Estados miembros, entre los que se encuentra España, por entender que podrían constituir ayudas de Estado prohibidas por el art. 107 del Tratado de Funcionamiento de la Unión Europea (TFUE). Estas actuaciones, que en principio se abrieron frente a aspectos tributarios particulares y específicos que afectaban a las cooperativas, pasaron a adquirir tintes más preocupantes, pues amenazaron con cuestionar la globalidad del régimen fiscal especial que tienen las cooperativas de algunos Estados de la Unión Europea. De las diferentes Decisiones y Sentencias de la Unión Europea que se han dictado nos ocupamos en este trabajo para conocer la diversidad de criterios que en dicho ámbito han ido desplegando las Instituciones.

\section{La justificación de los beneficios fiscales al cooperativismo en reconocimiento a las limitaciones de su régimen jurídico y económico y a su función social}

Las Instituciones de la Unión Europea han reconocido reiteradamente en varios de sus textos el papel que desarrollan las cooperativas dentro del tejido social y productivo y también las limitaciones de su modelo jurídico. Por ejemplo, en el documento Las cooperativas en la Europa de las empresas, de 7 de diciembre de 2001, la Comisión entendió que existían diferencias significativas entre las sociedades cooperativas y las sociedades típicamente capitalistas. Estas diferencias encontraron cabida y amparo en el Reglamento (CE) 1435/2003, Consejo, de 18 de agosto de 2003, del Estatuto de la sociedad cooperativa europea, hasta el punto que en la Comunicación de la Comisión al Consejo, al Parlamento Europeo, al Comité Económico y Social Europeo y al Comité de las Regiones sobre el fomento de las cooperativas en Europa, de 23 de febrero de 2004, la propia Comisión entendió que tales diferencias podrían justificar un tratamiento fiscal específico, siempre y cuando, en todos los aspectos relativos a la legislación sobre cooperativas, se respetase el principio según el cual cualquier protección o bene- 
ficio concedidos a un tipo específico de entidad debe ser proporcional a las limitaciones jurídicas, al valor social añadido o a las limitaciones inherentes a dicha fórmula societaria y no debe ser, en ningún caso, una fuente de competencia desleal. Asimismo, en el Dictamen sobre distintos tipos de empresa, aprobado por el Consejo Económico y Social Europeo el 1 de diciembre de 2009, se aboga por la introducción de medidas fiscales sectoriales que compensen a estas empresas sobre la base de su utilidad pública comprobada o de su contribución constatada al desarrollo regional (apartado 4.5.1.)

No obstante lo anterior, la posibilidad de aplicar un régimen fiscal específico y diferenciado para las cooperativas en la Unión Europea se encuentra sometido a grandes inconvenientes. Ello es así porque la Comisión empezó a enfocar la cuestión de su régimen fiscal desde la perspectiva de su compatibilidad con las ayudas de Estado prohibidas por el artículo 87 del Tratado de la Comunidad Europea (TCE) —ahora, como hemos visto, art. 107 TFUE - y sus trabajos hasta la fecha han apuntado hacia la aplicación de una concepción muy amplia del carácter selectivo de las medidas, que podría perjudicar seriamente las expectativas (inicialmente creadas) sobre la compatibilidad de ciertos regímenes fiscales especiales y el Derecho de la Unión Europea.

El régimen fiscal de las cooperativas en España comenzó a cuestionarse ante la Unión Europea en el año 2000, a raíz de la denuncia presentada por las asociaciones de empresarios de estaciones de servicio de Madrid y de Cataluña contra algunas medidas introducidas por el Real Decreto Ley 10/2000, de 6 de octubre; en particular, este Real Decreto Ley eliminó la prohibición hasta entonces establecida de distribuir gasóleo $\mathrm{B}$ a terceros no socios por parte de las cooperativas agrarias.

En un primer momento, la Comisión, en la Decisión 2003/293/CE, relativa a las medidas ejecutadas por España a favor del sector agrario tras el alza de los precios de los carburantes, de 11 de diciembre de 2002 (a la que nos referiremos también cono decisión inicial), asoció los beneficios fiscales concedidos a las cooperativas españolas con la naturaleza y la economía del sistema, dado que los retornos cooperativos soportaban una carga fiscal mayor que la de los dividendos de las sociedades mercantiles como consecuencia, por un lado, de las dotaciones obligatorias al FRO y al FEP y, por otro, del deficiente modelo de corrección de la doble imposición entre sociedad cooperativa y socio. Esta posición se correspondía con la postura mantenida en la Comunicación de la Comisión relativa a la aplicación del régimen de ayudas de Estado a las medidas de fiscalidad directa de las empresas (DOCE C 384, 10 de diciembre de 1998), que había establecido que estas ven- 
tajas constituían un beneficio excepcional al régimen general excluido del artículo 87 TCE (Hinojosa Torralvo, 2010, 81).

La Decisión de 11 de diciembre de 2002 fue recurrida, por lo que inició el procedimiento T-146/03, que concluyó mediante Sentencia dictada por el Tribunal de Primera Instancia (TPI) el 12 de diciembre de 2006, por la que anuló el artículo 1 de la Decisión en la medida en que declaró que las modificaciones del Real Decreto Ley 10/2000 no constituían una ayuda de Estado conforme al artículo 87.1 TCE.

De la resolución cabe destacar: en primer lugar, que no rechazó el régimen fiscal español aplicable a las cooperativas -obviamente, puesto que no era eso lo que se cuestionaba en el asunto, al menos de modo directo-; y en segundo lugar, que la causa de la anulación de la disposición de la Comisión, en la que se afirma que la medidas fiscales más beneficiosas de las cooperativas en el Impuesto sobre Transmisiones y Actos Jurídicos Documentados, el Impuesto sobre Actividades Económicas y el Impuesto sobre Bienes Inmuebles no tenían carácter selectivo a efectos de su caracterización como ayuda de Estado, es la falta de razonamiento suficientemente, por lo que su motivación fue puramente formalista (Hinojosa Torralvo, 2010, 81).

En consecuencia, hubiera bastado una justificación del carácter no selectivo de estas medidas fiscales a los efectos de no ser caracterizadas como ayudas de Estado, pero las cosas no discurrieron de este modo. El Proyecto de Decisión, fechado el 14 de abril de 2008, no resultó nada halagüeño para los intereses de las cooperativas y menos aún lo ha sido la definitiva Decisión de 15 de diciembre de 2009, que supone un radical viraje de la posición que la Comisión mantuvo en su Decisión inicial sobre el asunto en la que avaló y consideró plenamente acorde al Derecho de la Unión Europea la norma cuestionada. Por tanto, tomaremos esta Decisión como punto de partida de una nueva etapa en cuanto a la posición de la Comisión frente al régimen fiscal especial de las cooperativas.

\section{La revisión de los beneficios fiscales aplicables a las cooperativas en virtud del régimen de ayudas de Estado de la Unión Europea}

Como vemos, hasta no hace mucho tiempo el grado de tranquilidad en el sector de las cooperativas era elevado. Por todos es sabido que la existencia de regímenes fiscales preferentes para las cooperativas no era una novedad en Europa y, sin embargo, la Unión Europea no se había preocupado mucho, diríamos que casi nada, de examinarlos a la 
luz del régimen comunitario de ayudas de Estado, por lo que en muchos casos este examen versará sobre "ayudas existentes», y, por ello se van a encontrar con que los Estados miembros opondrán el principio de confianza legitima, si lo que pretendiera finalmente la Comisión, aunque ahora no lo parece, es que las cooperativas beneficiarias de las ayudas devolvieran las ya disfrutadas (Merino Jara 2009, 122).

El Borrador de Decisión de 14 abril de 2008 supuso, fuera de toda duda, un cambio de tendencia por cuanto en él se puso de manifiesto. La Comisión afirmó en este documento que la ampliación de las operaciones de las cooperativas con terceros sin perder los beneficios fiscales era una ayuda de Estado de carácter fiscal porque suponía necesariamente una pérdida de ingresos fiscales para el Estado correlativa con una menor tributación de las beneficiadas, que obtendrían así una ventaja impositiva. Continuó diciendo que esta ayuda fiscal afectaba a la competencia dentro de la Unión, porque las cooperativas agrarias realizan una actividad económica que consiste, en gran parte, en intercambios entre operadores económicos de los Estados miembros. Ello llevó a considerar, siempre de acuerdo con la Comisión, que las ayudas en cuestión tenían carácter selectivo, porque en relación a los impuestos propios de su régimen fiscal (Impuesto sobre Sociedades, Impuesto sobre Transmisiones y Actos Jurídicos Documentados e Impuesto sobre Bienes Inmuebles) la situación jurídica de las cooperativas no difería sustancialmente del resto de sociedades sujetas al régimen general, de modo que el beneficio era específico de las cooperativas por exclusión del resto de entidades.

Tocaba entonces analizar su posible justificación al amparo del art. 87.3 TCE. A este respecto, la Comisión llegó a la conclusión de que no podía justificarse que la medida estuviera motivada por las distorsiones del mercado producidas por la subida de los carburantes, esto es, que los apartados a) y b) del artículo 87.3 TCE no resultaban aplicables a este caso. Por otro lado, no cabía plantearse su justificación por los motivos de la letra d) y de la letra e) que ni siquiera habían sido contemplados 4 , por lo que solo quedaba su justificación al amparo de la letra c) — «las ayudas destinadas a facilitar el desarrollo de determinadas

\section{Art. 87.3 TCE. Podrán considerarse compatibles con el mercado común:}

a) las ayudas destinadas a favorecer el desarrollo económico de regiones en las que el nivel de vida sea anormalmente bajo o en las que exista una grave situación de subempleo;

b) las ayudas para fomentar la realización de un proyecto importante de interés común europeo o destinadas a poner remedio a una grave perturbación en la economía de un Estado miembro; 
actividades o de determinadas regiones económicas, siempre que no alteren las condiciones de los intercambios en forma contraria al interés común»- Entendió la Comisión que este precepto podría aplicarse en la medida en que las cooperativas cumplen los objetivos de política agrícola común del art. 33 del Tratado y, por tanto, contribuyen al interés general, pero para ello necesitan ser proporcionadas, en el sentido recogido en la Comunicación sobre el fomento de las cooperativas, de 23 de febrero de 2004. Es decir, que sólo las medidas que se enmarcaban en el carácter mutualista estaban justificadas, mientras que las que afectaban a operaciones realizadas con no socios solamente resultarían compatibles con el Tratado si tenían un impacto inapreciable sobre la competencia y esto se produciría, según la propia Comisión, cuando las cooperativas cumplieran las condiciones necesarias para ser consideradas como pequeñas o medianas empresas.

La Decisión definitiva, recaída el 15 de diciembre de 2009 (2010/473/UE) no sólo ha mantenido el carácter selectivo del régimen fiscal de las cooperativas españolas sino que ha ido más allá. La Comisión ha entendido que:

Por una parte, las medidas de favor se van a entender justificadas o no en virtud del criterio del «mutualismo puro». Esto es, sólo serán aceptables dichas medidas favorables respecto de las actividades de las cooperativas con sus propios socios, mientras que en las operaciones no mutualistas, la cooperativa actúa como las otras empresas y, por tanto, no merece trato alguno de favor en la imposición sobre sociedades.

Por otra parte, el régimen es una ayuda de Estado y además ilegal, por no haberse comunicado su elaboración a la Comisión, lo que obliga a su devolución. En este sentido, la recuperación de la ayuda tendría por objeto las ventajas fiscales concedidas por la parte de las actividades extracooperativas de las cooperativas que venden gasóleo $B$ rebasando el límite del 50\%, sin constituir una entidad jurídica distinta. Las ayudas deberían recuperarse de inmediato, a excepción de las ayudas concedidas a proyectos específicos que cumplían todas las condi-

c) las ayudas destinadas a facilitar el desarrollo de determinadas actividades o de determinadas regiones económicas, siempre que no alteren las condiciones de los intercambios en forma contraria al interés común;

d) las ayudas destinadas a promover la cultura y la conservación del patrimonio, cuando no alteren las condiciones de los intercambios y de la competencia en la Comunidad en contra del interés común;

e) las demás categorías de ayudas que determine el Consejo por decisión, tomada por mayoría cualificada, a propuesta de la Comisión. 
ciones establecidas en el Reglamento de minimis en el momento en que se concedieron, según nota de la propia Comisión.

Al margen de los excesos en que incurre la Decisión mencionada, que analizaremos seguidamente al hilo del recurso interpuesto contra la misma, parece conveniente reparar en el instrumento jurídico que utiliza la Comisión Europea —las normas que prohíben las ayudas de Estado- a fin de enjuiciar el régimen fiscal de las cooperativas establecido en algunos de los Estados miembros. Resulta reprobable la utilización de ésta una vía indirecta para lograr la armonización fiscal en la imposición directa y, en particular, de eliminar bonificaciones en el Impuesto sobre Sociedades, puesto que supone reconocer de manera implícita el fracaso de las vías específicamente dirigidas a tal fin (Rodrigo Ruiz 2010, 18).

La decisión fue recurrida con fecha 4 de abril de 2010 por Confederación Empresarial Española de la Economía Social (CEPES-España) y por la Confederación de Cooperativas Agrarias de España (CCAE) ante el Tribunal General, lo que ha dado lugar a la causa T-156/10. El recurso se fundamenta en cuatro motivos principales:

1. La violación del derecho de las partes interesadas en el procedimiento a ser oídas, al haber adoptado la Comisión la Decisión impugnada, que presenta conclusiones diametralmente distintas a las contenidas en la Decisión inicial, sin haber reabierto el procedimiento formal ni dado a las partes interesadas ocasión de presentar sus observaciones.

2. ${ }^{\circ}$ La infracción de los principios de seguridad jurídica y confianza legítima de las partes interesadas, al apartarse la Comisión del mandato de la Sentencia dictada en el asunto T-146/03, que sancionaba únicamente la ausencia de motivación suficiente en ciertos aspectos de la Decisión inicial y, en lugar de corregir dichos extremos, procede a revisar elementos de su Decisión Inicial no cuestionados por el juzgador

3. ' La incorrección de la consideración de la calificación de la medida como ayuda de Estado, en la medida en que se entiende que no basta afirmar que, por tener una fiscalidad diferente a las sociedades, las cooperativas agrarias que no siguen un modelo cooperativo mutualista puro disfrutan de una "ventaja», ignorando con ello que cooperativas y sociedades de capital no se encuentran en una situación ni fáctica ni jurídica similar. Y junto a esto, la consideración de que, incluso aceptando esta comparación, el régimen fiscal de las cooperativas no supondría una ventaja, sino diferencias justificadas por la economía y naturaleza del sistema fiscal español, como la propia Comisión 
había reconocido en la Decisión Inicial, no cuestionada en este punto por la sentencia de 12 de diciembre de 2006.

4. La insuficiente motivación y lo errado del análisis de la medida, a la luz de lo dispuesto en el artículo 107.3.c) TFUE (como sabemos, equivalente al art. 87.3.c) TCE), por lo que dicha medida hubiera debido declararse compatible.

Dejando a un lado estos fundamentos en los que se basa el recurso, no es de extrañar que se haya puesto de manifiesto la gran batería de razones que avalan una frontal oposición a la decisión, entre ellas su carácter incongruente, en sentido procesal y procedimental (porque no responde a las exigencias planteadas por la sentencia del TPI de la que trae causa) y la inseguridad jurídica en la que se ha producido; también el rechazo al criterio del mutualismo puro (que choca frontalmente con la realidad actual del modelo cooperativo y no está basado en ninguna norma europea, ni siquiera de soft law); y el desconocimiento que supone de la realidad cooperativa española (Hinojosa Torralvo 2010 83; Arana Landín 2010, 140).

Resulta imposible no destacar que no se pone en cuestión la avenencia del régimen fiscal de las cooperativas con el Tratado cuando se aplica a operaciones cooperativizadas. Desde esta perspectiva, no debería suscitar ningún problema el encaje de un régimen fiscal de este tenor con la normativa europea, cuando se reconoce por la propia Comisión que los criterios de orden mutual pueden respaldar un trato tributario diferenciado. Ahora bien, la justificación de este trato diferenciado y más favorable se sustenta también en otros argumentos igualmente poderosos y que no podemos obviar.

\section{Las bases para un cambio de tendencia: la sentencia del TJUE en el caso de las cooperativas italianas y la resolución del caso español}

El día 8 de septiembre de 2011 recayó al fin Sentencia del TJUE en las tres causas acumuladas (C-78/08 a C-80/08) que se han seguido a instancias de la Corte di Cassazione italiana, que cuestionó ante el órgano europeo si la regulación italiana de beneficios tributarios para las cooperativas, vigente hasta 2004, constituía una ayuda de Estado ilegítima que obligara a su devolución y si la utilización de la forma jurídica societaria de cooperativa constituía un abuso de derecho.

La sentencia nos ilustra acerca del marco jurídico nacional puesto en cuestión. Las cooperativas italianas se consideran sociedades de capital y están sujetas a una imposición sobre la renta estatal y a otra lo- 
cal. La imposición general sobre las sociedades de capital en Italia se basaba en el llamado principio de imposición única, según el cual los beneficios de la sociedad se gravaban en el impuesto de ésta (IRPEG) a tipos proporcionales así como a un impuesto local sobre la renta (ILOR), pero los útiles distribuidos a los socios se gravaban al tipo progresivo del impuesto personal de éstos (IRPEF); la doble imposición que pudiera producirse se eliminaba mediante un crédito de impuesto concedido al socio en su impuesto personal, crédito igual a la cantidad correspondiente pagada por los útiles por él recibidos en el impuesto societario. En la actualidad, los beneficios de las sociedades de capital se sujetan también a un impuesto proporcional (IRES) y los útiles distribuidos se siguen sometiendo al IRPEF: como quiera que el tipo en éste es de un $40 \%$, se ha introducido una exención del $60 \%$ para los útiles y dividendos de los socios de personas jurídicas ya sometidas al impuesto societario. A partir de 1973, las rentas de las cooperativas de producción y de trabajo regidas por principios mutualistas y sus consorcios quedaron exentas de la imposición sobre la renta, tanto estatal como local, siempre que la suma de las retribuciones efectivamente satisfechas a los socios no fueran inferiores al $60 \%$ de la suma total de los gastos, excepto los correspondientes a materias primas y asimilados. La exención se reducía a la mitad si esa relación bajaba del $60 \%$ pero no era inferior al 40\% (arts. 11 a 14 del Decreto del Presidente de la República 601/1973, de 29 de septiembre).

La sentencia supuso una tranquilidad relativa para el sector cooperativo, muy alarmado por el alcance general de este procedimiento. En el mismo se acumulan las siguientes causas:

a) Asunto C-78/08, que trata la denegación por parte de la Administración tributaria italiana del derecho de sociedad cooperativa Paint Graphos a las exenciones fiscales previstas por la normativa italiana en favor de las sociedades cooperativas por la vulneración y la aplicación errónea de los artículos 11 y 14 del DPR n. ${ }^{\circ} 601 / 1973$.

b) Asunto C-79/08, que versa sobre la pérdida de las ventajas fiscales previstas en los artículos 10 y siguientes del DPR n. ${ }^{\circ} 601 / 1973$, el aumento de su renta imponible en el ejercicio 1993 y el incremento consecutivo del IRPEG y del ILOR a los que Adige Carni, sociedad cooperativa italiana, estaba sujeta.

c) Asunto C-80/08, que discute, entre otras cuestiones relativas a las obligaciones fiscales de uno de sus socios, las exenciones concedidas en concepto del IRPEG referente a los años 1984 y 1985 a la cooperativa italiana Maricoltori. 
El órgano jurisdiccional nacional pregunta, mediante sus dos primeras cuestiones prejudiciales que se plantearon al TJUE, si las ventajas fiscales que el Derecho interno de que se trata otorga a las sociedades cooperativas son compatibles con el Derecho de la Unión y, en particular, si dichas ventajas pueden calificarse de "ayudas de Estado» con arreglo al artículo 87.1 TCE. La tercera cuestión hace referencia a modificaciones legislativas que tuvieron lugar en 2004, después de producirse los hechos del litigio principal (reforma del derecho de Sociedades italiano, especialmente en materia de cooperativas denominadas de mutualidad preponderante y no totalmente mutualísticas). Y la cuarta cuestión prejudicial es la relativa al eventual abuso de derecho cometido por las sociedades de que se trata en los litigios principales, pero en relación a ventajas exclusivamente establecidas por el Derecho interno italiano y no por el Derecho de la Unión Europea.

Las cuestiones tercera y cuarta se inadmiten por incompetencia del TJUE para resolver sobre las mismas al no suponer vulneraciones del Derecho de la Unión. Por ello, el Tribunal resuelve exclusivamente en relación las dos primeras cuestiones prejudiciales, en las que decide entrar "para proporcionar al órgano jurisdiccional remitente todos los elementos de interpretación pertenecientes al ámbito del Derecho de la Unión que puedan permitirle apreciar dicha compatibilidad para la resolución del asunto que le haya sido sometido» dado que no es competente, en el marco de un procedimiento con arreglo al artículo 267 TFUE, para pronunciarse sobre la compatibilidad de las normas de Derecho interno con el Derecho de la Unión ni para interpretar disposiciones legales o reglamentarias nacionales (párrafo 34).

Por tanto, lo pertinente es proporcionar al órgano jurisdiccional remitente los elementos de interpretación necesarios de los requisitos a los que el artículo 87.1 TCE, que supedita la calificación de una medida nacional como ayuda de Estado a: en primer lugar, la financiación de dicha medida por el Estado o mediante recursos estatales; en segundo lugar, la selectividad de tal medida; y en tercer lugar, la repercusión de ésta sobre los intercambios comerciales entre Estados miembros y la distorsión de la competencia resultante de la referida medida. Por tanto, procede a examinar sucesivamente esos tres requisitos y nosotros seguiremos el mismo esquema aunque aportando primero la conclusión a la que llega el Tribunal y después la argumentación que le conduce a la misma:

a) En cuanto al requisito de la financiación de la medida por el Estado o mediante recursos estatales: declara que la medida italiana constituye una financiación por el Estado. 
Partiendo de la premisa de que el concepto de ayuda es más general que el de subvención (según reiterada jurispudencia, en particular, las Sentencias de 8 de noviembre de 2001, as. Adria-Wien Pipeline y Wietersdorfer \& Peggauer Zementwerke, C-143/99; de 15 de julio de 2004, as. España v. Comisión, C-501/00; y de 10 de enero de 2006, as. Cassa di Risparmio di Firenze y otros, C-222/04), se deduce que "una medida mediante la cual las autoridades públicas conceden a determinadas empresas una exención tributaria que, aunque no implique una transferencia de fondos estatales, coloque a los beneficiarios de dicha medida en una situación financiera más favorable que a los restantes contribuyentes, constituye una «ayuda de Estado»» en el sentido del artículo 87.1 TCE (párrafo 46).

b) Sobre el requisito de selectividad de la medida controvertida: declara que el órgano jurisdiccional remitente deberá apreciar si las ventajas fiscales previstas en favor de las sociedades cooperativas de producción y de trabajo italianas se ven justificadas por la naturaleza y la economía general del sistema fiscal en cuestión.

Según el TJUE, a la luz del régimen fiscal común o «normal» aplicable, «debe apreciarse y determinarse el eventual carácter selectivo de la ventaja otorgada por la medida fiscal de que se trate, demostrando que dicha medida supone una excepción al referido régimen común, en la medida en que introduce diferenciaciones entre operadores económicos que, con respecto al objetivo asignado al sistema fiscal de dicho Estado miembro, se encuentran en una situación fáctica y jurídica comparable» (párrafo 49).

El Tribunal encuentra que el citado régimen fiscal común de referencia lo constituye la regulación de la imposición sobre sociedades que grava el beneficio neto resultante del ejercicio de la actividad de las mismas al final del año de imposición. Pues bien, como excepción a la regla generalmente aplicable a las personas jurídicas, los beneficios imponibles de las sociedades cooperativas de producción y de trabajo de que se trata están exentos del impuesto sobre sociedades. Por tanto, esas sociedades cooperativas disfrutan de una ventaja fiscal que se otorga en función de la forma jurídica de la empresa, (dependiendo que sea o no una sociedad cooperativa) (art. 11 del DPR n. ${ }^{\circ} 601 / 1973$ ).

Por tanto, de lo que se trata es de examinar si este tipo de exenciones fiscales pueden favorecer a determinadas empresas o producciones en relación con otras empresas que se encuentren en una situación fáctica y jurídica comparable, habida cuenta del objetivo perseguido por el régimen de este impuesto sobre sociedades. A este respecto, los apartados 55 a 62 de la Sentencia dan buena cuenta de las caracterís- 
ticas específicas propias de las sociedades cooperativas que, en principio, niegan que las sociedades cooperativas de producción y de trabajo como aquéllas de que se trata en los litigios principales se encuentren en una situación de hecho y de Derecho comparable a las de las sociedades comerciales, dado que las sociedades cooperativas actúan persiguiendo el interés económico de sus socios y mantienen con éstos una relación no meramente comercial, sino personal particular, en la que los socios están activamente implicados y tienen derecho a un reparto equitativo de los resultados económicos.

Pero el TJUE va más allá al entender que, incluso, en el supuesto de que el juez nacional llegase a la conclusión de que, en los litigios de que conoce, esto efectivamente se cumple, "aún sería preciso determinar, con arreglo a la jurisprudencia del Tribunal de Justicia, si las exenciones fiscales de que se trata en el litigio principal encuentran justificación en la naturaleza o en la economía general del sistema en el que se inscriben» (párrafo 64).

Tras esta contextualización, los apartados 67 a 75 se dedican a proporcionar precisiones jurídicas al órgano remitente que le permitan pronunciarse sobre los litigios de que conoce. Estas precisiones son las siguientes:

1. a La finalidad perseguida por las intervenciones estatales no basta para que, en principio, eviten la calificación de «ayudas» en el sentido del artículo 87 TCE.

2. ${ }^{a}$ El artículo 87.1 TCE no distingue según las causas o los objetivos de las intervenciones estatales, sino que los define en función de sus efectos.

3. ${ }^{a}$ Una medida que establece una excepción a la aplicación del sistema fiscal general puede verse justificada si dicha medida se deriva directamente de los principios fundadores o rectores de dicho sistema fiscal.

4. ${ }^{\text {a }}$ Las exenciones fiscales resultantes de un objetivo ajeno al sistema de imposición en el que se inscriben no podrán eludir las exigencias derivadas del artículo 87.1 TCE.

5. ${ }^{a}$ La Comisión considera que la naturaleza o la economía general del sistema fiscal nacional puede invocarse válidamente para justificar que las sociedades cooperativas que distribuyen a sus miembros todos sus beneficios no estén gravadas como tales, en la medida en que se exige el pago del impuesto a sus miembros (tal como se desprende del punto 25 de la Comunicación relativa a la fiscalidad directa de las empresas).

6. ${ }^{a}$ La Comisión también considera que una medida nacional no puede verse válidamente justificada por la naturaleza o la eco- 
nomía general del sistema fiscal de que se trate si permite la exención del impuesto sobre los beneficios procedentes de intercambios con terceros no socios de la cooperativa o la deducción de importes abonados a estos últimos en concepto de remuneraciones.

7. ${ }^{\text {a }}$ Debe velarse por el respeto de la exigencia de coherencia de una ventaja otorgada no sólo con las características inherentes del sistema fiscal de que se trate, sino también con la aplicación de dicho sistema.

8. ${ }^{a}$ Corresponde al Estado miembro de que se trate establecer y aplicar procedimientos de control y vigilancia apropiados a efectos de garantizar la coherencia de las medidas fiscales específicas adoptadas en favor de las sociedades cooperativas con la lógica y la economía general del sistema fiscal, así como evitar que las entidades económicas opten por esta forma jurídica específica con el único fin de disfrutar de las ventajas en materia de impuestos previstas para este tipo de sociedades.

9. ${ }^{a}$ Para que exenciones fiscales como aquéllas de que se trata en los litigios principales puedan verse justificadas por la naturaleza o la economía general del sistema fiscal del Estado miembro afectado, todavía habrá que comprobar que son conformes al principio de proporcionalidad y no exceden los límites de lo necesario, en el sentido de que el objetivo legítimo perseguido no podría lograrse mediante medidas de menor alcance.

c) En lo tocante a los requisitos relativos a la repercusión sobre los intercambios comerciales entre los Estados miembros y la distorsión de la competencia: declara que una ventaja fiscal como aquélla de que se trata en los litigios principales puede afectar a los intercambios comerciales entre los Estados miembros y falsear la competencia en el sentido del artículo 87.1 TCE.

Esta conclusión se deduce partiendo de que, a los efectos de la calificación como ayuda de Estado de una medida nacional, no es necesario acreditar la incidencia real de la ayuda sobre los intercambios comerciales entre los Estados miembros y el falseamiento efectivo de la competencia, sino únicamente examinar si tal ayuda puede afectar a dichos intercambios y falsear la competencia (en reiterada jurisprudencia como la de las Sentencias de 29 de abril de 2004, Italia/Comisión, C-372/97; de 15 de diciembre de 2005, Unicredito Italiano, C-148/04; y Cassa di Risparmio di Firenze y otros ya citada.)

En virtud de todo lo expuesto, el fallo del TJUE declara que: «Las exenciones fiscales como aquéllas de que se trata en los litigios princi- 
pales, otorgadas a las sociedades cooperativas de producción y de trabajo en virtud de una normativa nacional de las características de la del artículo 11 del Decreto del Presidente de la República n. ${ }^{\circ}$ 601, de 29 de septiembre de 1973, por el que se regulan las ventajas fiscales, en su versión vigente de 1984 a 1993, sólo constituyen una "ayuda de Estado» con arreglo al artículo 87 CE, apartado 1, cuando se cumplen todos los requisitos de aplicación de dicha disposición. Por lo que atañe a una situación como la que dio lugar a los litigios de que conoce el órgano jurisdiccional remitente, corresponderá a éste apreciar más concretamente el carácter selectivo de las exenciones fiscales de que se trata, así como su eventual justificación por la naturaleza o la economía general del sistema fiscal nacional en el que se inscriben determinando, en particular, si las sociedades cooperativas de que se trata en los litigios principales se encuentran, de hecho, en una situación comparable a la de otros operadores constituidos como entidades jurídicas con ánimo de lucro y, si eso es efectivamente lo que ocurre, si el trato fiscal más favorable reservado a dichas sociedades cooperativas es, por una parte, inherente a los principios esenciales del sistema de imposición aplicable en el Estado miembro de que se trata y, por otra parte, conforme a los principios de coherencia y de proporcionalidad».

La importancia de este caso dentro de la Unión Europea en general, y para España en particular, es indudable, puesto que el TJUE deja la puerta abierta a la posible consideración del sistema italiano de beneficios fiscales a las cooperativas sea considerado una "ayuda de Estado» con arreglo al artículo 87 TCE. Hubiera sido deseable una mayor contundencia por parte del órgano jurisdiccional, como la que manifestó el Abogado general (AG) Niilo Jääskinen, en sus conclusiones del de 8 de julio de 2010, que nosotros suscribimos. De ellas se deduce que:

En primer término - después de un repaso a las notas características de las cooperativas y a su tratamiento fiscal, incluidas sugerentes reflexiones sobre el principio mutualista, el papel de los retornos cooperativos y la conexión entre el régimen fiscal específico que existe en distintos Estados miembros y la estructura de su capital, el sistema económico que les es propio y sus fines constitucionales (art. 45 Constitución italiana)—, que este tipo de sociedades operan en un ámbito jurídico y económico específico (párrafo 45).

En segundo término - tras un análisis formal pero exhaustivo de los requisitos de la noción de ventaja y de selectividad a efectos del art. 87.1 TCE (el propio AG aclara que utiliza la numeración correspondiente a este Tratado y no al TFUE) - , que las medidas italianas no son selectivas, porque las cooperativas italianas de producción y trabajo no se encuentran en una situación comparable a la de las sociedades con 
ánimo de lucro ni a las de otras sociedades cooperativas no mutualistas (apartado 112).

Finalmente, concluye que no puede considerarse ayuda de Estado a efectos del art. 87.1 TCE un régimen fiscal de las cooperativas de producción y de trabajo cuyo contenido sea la exención de la renta correspondiente al beneficio obtenido con el trabajo de los socios, como el italiano de 1973, porque ese régimen deriva directamente de los principios fundadores del sistema fiscal aplicable a las sociedades cooperativas.

A nuestro entender, a partir de las conclusiones del AG se puede defender que las medidas que producen un ahorro de gastos fiscales para empresa, bien articuladas, son adecuadas y proporcionadas a la incidencia económica y a la dimensión social de las cooperativas y de otras entidades de economía social y, por ende, que la política fiscal puede ser un instrumento eficaz para fomentar y desarrollar el modelo cooperativo.

En este contexto llega el Auto del Tribunal General que resuelve el recurso presentado por la Confederación Empresarial Española de la Economía Social (CEPES-España) y por la Confederación de Cooperativas Agrarias de España (CCAE) ante el Tribunal General para anular la Decisión de la Comisión de 2010, aduciendo fundamentalmente:

- su carácter incongruente, porque excede el petitum, que nunca fue la ilegalidad del régimen fiscal de las cooperativas en su conjunto:

- el rechazo al criterio del mutualismo puro, que choca frontalmente con la realidad del modelo cooperativo y no está basado en ninguna norma europea, ni siquiera de softlaw;

- y también el desconocimiento que supone de la realidad cooperativa española, que solo establece beneficios fiscales para las operaciones de la cooperativa con sus socios.

Para entender la escasa repercusión que ha tenido esta resolución - a pesar de la gran expectación que el asunto despertó durante un tiempo-, hay que señalar dos cosas:

En cuanto al fondo, que las medidas controvertidas fueron modificadas por la disposición final cuadragésima segunda de la Ley 2/2011 de Economía Sostenible. Así, a partir del 1 de enero de 2011 las cooperativas agrarias pueden distribuir productos petrolíferos a terceros sin perder la condición fiscal de «cooperativas especialmente protegidas» a condición de que tales operaciones no superen el 50\% del volumen total de las operaciones realizadas por las cooperativas con sus socios. De este modo, cumpliendo la regulación actual no hay riesgo de supe- 
rar el umbral de minimis ${ }^{5}$. Pero es que incluso durante la vigencia del RD Ley que permitió la venta de gasóleo $B$ a terceros sin limitación, ninguna de las cooperativas beneficiadas por la medida superó ese umbral, tal y como informó el Estado español al Tribunal cuando inició el procedimiento de recuperación impuesto por la Decisión cuya anulación se pedía.

En cuanto a la forma, que el Tribunal no consideró a las demandantes legitimadas activamente para ejercitar la acción puesto que un recurso de anulación debe ser promovido por una persona física o jurídica en la medida en que tenga interés en obtener la anulación del acto impugnado. $Y$ las demandantes ni siquiera demostraron, a juicio del Tribunal, que las cooperativas a las que representan fueran beneficiarias efectivas de las ayudas individuales concedidas en el marco de las medidas controvertidas. Ello determinó la inadmisión del recurso.

\section{Notas conclusivas}

No es baladí que recordemos que el movimiento cooperativo asienta sus raíces en un pueblo de Inglaterra llamado Rochadle, donde, en 1844, un grupo de trabajadores de la industria textil formaron una cooperativa llamada «la Sociedad Equitativa de Pioneros de Rochdale», tras vivir en carne propia el desamparo social. Una cooperativa, por tanto, es un tipo diferente de empresa, con unos valores y una ética distinta a la del mercado. Es un modelo de empresa que respeta los principios de ayuda mutua y sostenibilidad, controlado por las personas de la comunidad, con participación democrática, justicia y transparencia.

Pero esto ha de combinarse necesariamente con la articulación de sociedades cómodas y flexibles, que los socios no se vean encorsetados por un régimen económico, fiscal y social muy estricto y, sobre todo, que no sea un modelo transitorio para después transformar la cooperativa en una sociedad mercantil por las limitaciones de expansión empresarial que el régimen legal de aquéllas presenta. El legislador cooperativo debe combinar ambos aspectos: seguridad en el tráfico y tipos sociales dinámicos y todo eso con el obligado respeto de los principios cooperativos. Este equilibrio no es fácil de alcanzar como lo demuestra

5 El Reglamento (CE) n. ${ }^{\circ}$ 1998/2006 de la Comisión, de 15 de diciembre de 2006, relativo a la aplicación de los artículos [107 TFUE] y [108 TFUE] establece el umbral de minimis en el momento de su concesión en $200.000 €$ durante cualquier período de tres ejercicios fiscales. 
la incesante labor de reforma de las leyes cooperativas españolas y el trabajo inacabado de las Instituciones europeas.

El sistema jurídico debe proteger la economía social puesto que las cooperativas en España son el motor del desarrollo regional en muchas zonas, de tal forma que, su posible desaparición generaría un gran trastorno en su entorno social. Esta pérdida sería traumática para numerosos socios, que considerarían inaceptable que la entidad orgullo local, se transformara en una sociedad mercantil, con los riesgos de deslocalización que ello conlleva (Vargas Vasserot, Gadea y Sacristán 2015, 253).

Intentar restringir el trato fiscal aplicable a las cooperativas y considerarlo ayudas de Estado, supone poner trabas que pueden conducir a largo plazo a la salida del mercado de esta forma societaria, dado que se las situará en una posición de desventaja respecto a las sociedades de capital. La Comisión Europea ha de sopesar que cualquier decisión que afecte negativamente a las cooperativas pondría en cuestión su compromiso con respecto al singular modelo de empresa que representan. No se trata solo de adoptar medidas de ajuste; si se entiende, como entendemos nosotros, que las cooperativas cumplen fines de interés general, tienen que adoptarse también medidas de fomento (Merino Jara 2009, 128). Las cooperativas representan una forma societaria responsable en la medida en que realizan funciones públicas y que, haciéndolo, coadyuvan al sostenimiento de los gastos públicos. La introducción de beneficios fiscales diseñados para fomentar los valores éticos de la empresa — sociales y laborales fundamentalmente- no solo es una necesidad política y social sino que, a su vez, puede abrir el camino hacia una solución para evitar la pérdida de competitividad de las cooperativas en el mercado (Aguilar Rubio 2015, 377).

Las cooperativas están adquiriendo cada vez más importancia en la Unión Europea, donde existen alrededor de 160.000 empresas cooperativas, que pertenecen a 123 millones de miembros y proporcionan empleo a 5,4 millones de personas (incluidas unas 50.000 cooperativas en los sectores de la industria y los servicios en las que trabajan 1,4 millones de personas), y contribuyen aproximadamente en un 5\%, de media al PIB de los Estados miembros ${ }^{6}$. Asimismo, durante los últimos años, se han creado cientos de cooperativas industriales y de servicios debido a la reestructuración de empresas en crisis o sin sucesor, salvando y revitalizando así actividades económicas y puestos de trabajo a escala local y los grupos de cooperativas industriales y de servicios han

6 Datos extraídos de PE 2012/2321(INI)): Informe sobre la contribución de las cooperativas a la salida de la crisis, 2013, p. 4. 
influido de forma notable en el desarrollo regional de algunas de las regiones más industrializadas de la Unión Europea. Las cooperativas «sociales» especializadas en la integración laboral proporcionan empleo a más de 30.000 personas discapacitadas o desfavorecidas en los sectores de la industria y los servicios. A su vez, las cooperativas se han convertido en un modelo para los trabajadores autónomos y las profesiones liberales y han adquirido notable importancia en nuevos sectores ${ }^{7}$. Ello deja constancia del importante papel que desempeñan las cooperativas en la Unión Europea en términos económicos, sociales, laborales y de desarrollo sostenible ${ }^{8}$.

\section{Bibliografía}

AGUILAR RUBIO, Marina. 2015. Los principios cooperativos en la legislación tributaria. CIRIEC-España, Revista Jurídica de Economía Social y Cooperativa, n. ${ }^{\circ} 27$.

AGUILAR RUBIO, Marina. 2012, 40 años de historia de las empresas de participación. Lejarriaga Pérez de las Vacas, Martín López y Muñoz García (Dirs). Madrid: Versus.

ALGUACIL MARÍ, María del Pilar. 2010. Condicionantes del régimen de ayudas de Estado en la fiscalidad de cooperativas. CIRIEC-España, Revista de Economía Pública, social y cooperativa, n. ${ }^{\circ} 69$.

ALGUACIL MARÍ, María del Pilar. 2003, Tratamiento fiscal de las cooperativas a la luz del régimen europeo de ayudas de Estado» CIRIEC-España, Revista Jurídica de Economía Social y Cooperativa, n. ${ }^{\circ} 14$.

ARANA LANDÍN, Sofia. 2010. La nueva regulación sobre operaciones vinculadas y su incidencia en las Cooperativas, CIRIEC-España, Revista de Economía Pública, social y cooperativa, n. ${ }^{\circ} 69$.

CALVO ORTEGA, Rafael. 2005. Entidades de economía social: razones de una fiscalidad específica. Fiscalidad de las entidades de economía social. Madrid: Thomson-Civitas.

CALVO ORTEGA, Rafael. 2005. La sociedad cooperativa europea: un paso adelante en la fiscalidad de la economía social, Fiscalidad de las entidades de economía social. Madrid: Thomson-Civitas.

7 En referencia a actividades como los servicios sociales o de atención sanitaria, los servicios digitales y de apoyo empresarial y los servicios de interés general prestados anteriormente por el sector público (por ejemplo, servicios medioambientales y gestión de espacios naturales, educación y cultura, y producción de energía a partir de fuentes renovables.)

8 Este rol, junto con el reconocimiento a su contribución al logro del objetivo de desarrollo económico y social sostenible de las comunidades regionales y locales se han visto reforzados por la Estrategia Europa 2020 y por el programa Horizonte 2020. 
GADEA, Enrique. 1999. Análisis de los directrices generales de la legislación sobre cooperativas en España. Boletín de la Asociación Internacional de Derecho Cooperativo, n. ${ }^{\circ} 32$.

HINOJOSA TORRALVO, Juan José. 2010. Fiscalidad y financiación de las cooperativas: ¿a qué juega la Unión Europea? CIRIEC-España, Revista de Economía Pública, social y cooperativa, n. ${ }^{\circ} 69$.

MARTíN FERNÁNDEZ, Javier, Martín Salcines, Francisco y Rodriguez Márquez, Jesús. 2006. Cuestiones tributarias y contables de las Cooperativas. Madrid: Iustel.

MERINO JARA, Isaac. 2009. El vigente régimen fiscal de las cooperativas a la luz de las ayudas de Estado. CIRIEC-España, Revista de Economía Pública, social y cooperativa, n. ${ }^{\circ} 66$.

RODRIGO RUIZ, Marco Antonio. 2010. Consideraciones sobre el régimen fiscal de las cooperativas. Problemas actuales y líneas de reforma, CIRIEC-España, Revista de Economía Pública, social y cooperativa, n. ${ }^{\circ} 69$.

TEJERIZO LÓPEZ, José Manuel. 2010. Algunas reflexiones sobre el régimen fiscal de las cooperativas. CIRIEC-España, Revista de Economía Pública, social y cooperativa, $\mathrm{n} .{ }^{\circ} 69$.

VARGAS VASSEROT, Carlos (coord), Gadea, Enrique y Sacristán, Fernando. 2015. Derecho de las Sociedades Cooperativas. Madrid: La Ley. 


\section{Derechos de autor}

El Boletín de la Asociación Internacional de Derecho Cooperativo es una revista de acceso abierto lo que significa que es de libre acceso en su integridad inmediatamente después de la publicación de cada número. Se permite su lectura, la búsqueda, descarga, distribución y reutilización legal en cualquier tipo de soporte sólo para fines no comerciales y según lo previsto por la ley; sin la previa autorización de la Editorial (Universidad de Deusto) o el autor, siempre que la obra original sea debidamente citada (número, año, páginas y DOI si procede) y cualquier cambio en el original esté claramente indicado.

\section{Copyright}

The International Association of Cooperative Law Journal is an Open Access journal which means that it is free for full and immediate access, reading, search, download, distribution, and lawful reuse in any medium only for non-commercial purposes, without prior permission from the Publisher or the author; provided the original work is properly cited and any changes to the original are clearly indicated. 